\title{
Cigarette smoking and Awareness of Oral Health Problems of Tobacco use among Students at the University of Port Harcourt, South-South Nigeria
}

\author{
${ }^{1}$ Braimoh Omoigberai Bashiru, ${ }^{2}$ Umanah Ayamma Udo
}

\begin{abstract}
Objectives: Cigarette smoking is recognized as the most important environmental risk factor in periodontitis and also an important risk factor for oral cancer. The aim of this study was to determine the prevalence of cigarette smoking and awareness of oral health problems of tobacco use among university students in Port Harcourt, Nigeria.
\end{abstract}

Materials and methods: The study population consisted of 360 young adults: $188(52.2 \%)$ males and $172(47.8 \%)$ females. Participants answered questions regarding demography, smoking behavior, attitude and on oral effect of smoking. Data were analyzed using IBM SPSS (New York, USA) statistics version 20.0 and test of significance done using Chi-square.

Results: The overall prevalence of smoking was 78 (21.7\%): 52 $(27.7 \%)$ in males and $26(15.1 \%)$ in females. Males significantly smoked more than females $(p=0.002)$. Fifty-one $(65.4 \%)$ of the current smokers commenced smoking in secondary school, $39(50 \%)$ had smoked for 6 to 10 years, $54(69.2 \%)$ consumed one to five sticks of cigarettes per day and among those who quitted smoking, 39 (52\%) stopped smoking for health reasons. While $262(72.8 \%)$ were ignorant that smoking was harmful to oral health, $223(61.9 \%)$ and $278(77.2 \%)$ respectively could not identify smoking as a risk factor for oral cancers and gum disease.

Conclusion: Though majority of the students were aware of the negative impact of smoking on general health, most of them were ignorant of the effect on oral health. Therefore, shared risk approach should be employed to inform, guide and educate the public on the effects of tobacco and in the campaign against its use.

Keywords: Awareness, Oral health, Smoking, University students.

How to cite this article: Bashiru BO, Udo UA. Cigarette smoking and Awareness of Oral Health Problems of Tobacco

\footnotetext{
${ }^{1}$ Senior Lecturer, ${ }^{2}$ Lecturer 1

${ }^{1}$ Department of Preventive Dentistry, Faculty of Dentistry College of Health Sciences, University of Port Harcourt, Choba Rivers State, Nigeria

${ }^{2}$ Department of Restorative Dentistry, Faculty of Dentistry College of Health Sciences, University of Port Harcourt, Choba Rivers State, Nigeria

Corresponding Author: Braimoh Omoigberai Bashiru, Senior Lecturer, Department of Preventive Dentistry, Faculty of Dentistry College of Health Sciences, University of Port Harcourt, Choba Rivers State, Nigeria, Phone: 08033562187, e-mail: omoigberai. braimoh@uniport.edu.ng
}

use among Students at the University of Port Harcourt, SouthSouth Nigeria. World J Dent 2014;5(4):209-212.

\section{Source of support: Nil}

Conflict of interest: None

\section{INTRODUCTION}

Smoking contributes to the global burden of diseases especially chronic noncommunicable diseases including cardiovascular diseases, respiratory diseases, cancers, stroke and oral diseases. It is a common preventable cause of morbidity and mortality worldwide. ${ }^{1}$ World Health Organization (WHO) estimates that death resulting from smoking, will decrease by $9 \%$ by 2030 in the developed countries, while this is expected to double in the developing countries. ${ }^{1-4}$ Approximately, 80\% of the over 1.2 billion smokers in the world live in the developing countries. ${ }^{2,3}$ Globally, about 5 million people die annually from the use of tobacco and this is expected to rise to 10 million by the year $2025 .^{2}$ It is estimated that approximately 7 million of these will be from developing countries. ${ }^{2}$ Worldwide, about $12 \%$ of women and $47 \%$ of men smoke. In developing countries, $7 \%$ of women and $48 \%$ of men smoke, the situation is different in developed countries, where $24 \%$ of women smoke as compared to $42 \%$ of men. ${ }^{2}$

The effects of smoking on oral tissues include reduced taste perception, staining of teeth, palatal keratosis, melanosis, oral candidiasis, ${ }^{5}$ halitosis and dental caries. The relationship between smoking and oral hygiene status is also well established. Smokers have been found to accumulate more plaque and calculus, have more oral health problems and less likely to visit dentists than nonsmokers. ${ }^{6-9}$ Tobacco smoking particularly in the form of cigarette is an important environmental risk factor in periodontitis, oral cancers and precancers. ${ }^{5,10}$ It also has an adverse effect on almost all forms of periodontal therapy and increases the severity of periodontal disease. ${ }^{5}$ The complication of smoking in pregnancy includes premature deliveries, low birth weight, spontaneous abortion and perinatal mortality. ${ }^{5}$

Student period is the time when most behavioral traits are developed and established. Most students start smoking during this period due to peer pressure. 
Although number of studies on cigarette smoking among students in higher educational institutions in Nigeria has been reported, ${ }^{11-14}$ none of these studies has focused on the awareness of oral health problems among smokers in higher institution of learning. In addition, while some of these studies have been done in other regions of the country including South West, Northeast and North Central, ${ }^{11-14}$ there is paucity of data in the South-South region, particularly Port Harcourt Rivers State. Therefore, this study is necessary to provide baseline data for epidemiological and comparative purposes. The aim of this study was to determine the prevalence of cigarette smoking and awareness of oral health problems of tobacco use among university students in Port Harcourt, South-South Nigeria.

\section{MATERIALS AND METHODS}

The cross-sectional epidemiological survey was conducted among undergraduate students at the University of Port Harcourt, Rivers State, Nigeria, in January 2014. The students were recruited at the ceremonial pavilion in the Abuja Campus of the University of Port Harcourt. Students from various departments of the University often congregate at the pavilion to receive lectures. The tool for data collection was pretested intervieweradministered questionnaire. The questionnaire was pretested on 25 randomly selected individuals a week prior to the survey, and changes made before the questionnaires were finally administered to the participants. The questionnaire contained questions on demography, smoking behavior and attitude and oral effect of smoking. The protocol for the study was approved by the Research and Ethics Committee of the University of Port Harcourt and informed consent obtained from the students after explaining the objective of the study. Data were analyzed using IBM SPSS statistics (New York, USA) version 20.0. Significant testing was done using Chi-square with $\mathrm{p}<0.05$ considered statistically significant.

\section{RESULTS}

A total of 360 students completed the questionnaire. This comprised of 188 (52.2\%) males and 172 (47.8\%) females. The overall prevalence of smoking was 78 (21.7\%): $52(27.7 \%)$ in males and $26(15.1 \%)$ in females. Males significantly smoked more than females $(p=0.002)$ and females were significantly $(p=0.001)$ likely not to have smoked than males (Table 1).

Among the current smokers, 7 (9\%) had smoked for less than 1 year, 24 (30.8\%) for 1 to 5 years, 39 (50\%) for 6 to 10 years and $8(10.2 \%)$ for over 10 years. The majority $54(69.2 \%)$ of current smokers consumed one to five sticks of cigarettes per day; whereas, 24 (30.8\%) smoked six to ten
Table 1: Prevalence of smoking among the students

\begin{tabular}{|c|c|c|c|c|c|c|}
\hline \multirow[b]{2}{*}{ Respondents } & \multicolumn{2}{|c|}{ Male } & \multicolumn{2}{|c|}{ Female } & \multicolumn{2}{|c|}{ Total } \\
\hline & $N$ & $\%$ & $N$ & $\%$ & $N$ & $\%$ \\
\hline $\begin{array}{l}\text { Current } \\
\text { smokers }\end{array}$ & 52 & 27.7 & 26 & 15.1 & 78 & 21.7 \\
\hline Never smoked & 91 & 48.4 & 116 & 67.5 & 207 & 57.5 \\
\hline Quit smoking & 45 & 23.9 & 30 & 17.4 & 75 & 20.8 \\
\hline Total & $\begin{array}{l}188 \\
(52.2 \%)\end{array}$ & 100 & $\begin{array}{l}172 \\
(47.8 \%)\end{array}$ & 100 & 360 & 100 \\
\hline
\end{tabular}

Table 2: Smoking attitude and behavior among students

\begin{tabular}{lll}
\hline Variables & Frequency & Percentage \\
\hline $\begin{array}{l}\text { Duration of smoking in years } \\
\text { < 1 year }\end{array}$ & 7 & 9.0 \\
1-5 years & 24 & 30.8 \\
6-10 years & 39 & 50.0 \\
>10 years & 8 & 10.2 \\
Time of commencing smoking & & \\
Secondary school & 51 & 65.4 \\
University & 27 & 34.6 \\
Number of cigarette sticks & & \\
smoked daily & & \\
1-5 & 54 & 69.2 \\
6-10 & 24 & 30.8 \\
$\begin{array}{l}\text { Reason for quitting smoking } \\
\text { Health reasons }\end{array}$ & 39 & \\
$\begin{array}{l}\text { Personal decision } \\
\text { Pressure from parents }\end{array}$ & 13 & 52 \\
and relatives & 20 & 26.7 \\
No money & & \\
\hline
\end{tabular}

sticks of cigarettes daily. While 51 (65.4\%) of the current smokers commenced smoking in secondary school, 27 (34.6\%) started smoking after entering the university. Among those who quitted smoking, 39 (52\%) quit smoking for health reasons, 20 (26.7\%) due to pressure from parents and relatives, $13(17.3 \%)$ took a personal decision to stop smoking, and only 3 (4\%) stopped for economic reasons (Table 2).

On the effects of smoking on general and oral health, $305(84.7 \%)$ agreed that smoking was dangerous to the smoker's health, whereas 241 (66.9) were ignorant that cigarette smoking was harmful when passively inhaled. Furthermore, while 262 (72.8\%) were ignorant that smoking was injurious to oral health, 261 (72.5\%) identified smoking as a cause of bad breath and 243 (67.5\%) thought it could cause staining of teeth. Two hundred and twenty-three (61.9\%) and 278 (77.2\%) respectively did not recognize that smoking could cause oral cancers and gum disease. Nonsmokers were significantly aware of the oral effects of smoking than smokers for all knowledge statements (Table 3). The sources of information on the effect of smoking on health was educational curricula, 151 (42\%); advertisement through media, 176 (48.8\%) and 33 $(9.2 \%)$ from other sources, such as the internet, magazines, friends and family members. 
Table 3: Knowledge of oral effects of smoking among the students ${ }^{\varphi}$

\begin{tabular}{lllll}
\hline Oral effects of smoking & $\begin{array}{l}\text { Positive } \\
\text { response N (\%) }\end{array}$ & Smokers & Nonsmokers & p-value \\
\hline Smoking is harmful to smoker's health & $305(84.7)$ & 17.1 & 82.9 & 0.000 \\
Smoking is harmful to nonsmoker's health & $119(33.1)$ & 17.6 & 82.4 & 0.000 \\
Smoking is harmful to oral health & $98(27.2)$ & 18.4 & 81.6 & 0.000 \\
Smoking causes staining of teeth & $243(67.5)$ & 18.1 & 81.9 & 0.001 \\
Smoking causes oral cancer & $137(38.1)$ & 21.2 & 78.8 & 0.001 \\
Smoking causes gum disease & $82(22.8)$ & 22.0 & 78 & 0.000 \\
Smoking causes change in color of soft & $168(46.7)$ & 25.4 & 74.6 & 0.002 \\
tissues in the mouth & & & & 0.001 \\
Smoking causes bad breath & $261(72.5)$ & 24.1 & 75.9 & 0.9
\end{tabular}

${ }^{\varphi}$ For the purpose of comparing the knowledge of oral effects of smoking among the samples, the population was dichotomized into smokers (currently smoking), and nonsmokers (quit smoking and never smoked)

\section{DISCUSSION}

The smoking tobacco constitutes public health problem in the developing world. The health hazards of smoking are well documented, and prevention of smoking is the single greatest opportunity for preventing noncommunicable disease in the world presently. ${ }^{13}$ The prevalence of cigarette smoking in the present study was higher when compared with earlier studies reported on students of a higher institutions in Nigeria. ${ }^{12,14}$ This result obtained was also higher compared to prevalence reported among medical students in Kenya, 9.3\%; China, 6\%; Indian, $7 \%$ and Thailand, $7 \% .{ }^{17}$ Study design together with environmental, social, cultural and economic factors might be responsible for this difference. However, the prevalence rate obtained in this study was comparable to a study carried out among medical and nonmedical students in Ilorin, where higher rate of smoking was reported among nonmedical students. The high prevalence of cigarette smoking reported in this study may be because they are less aware of the harmful effect of smoking on health related to medical students. Other research may be needed to confirm this.

The higher rate of smoking observed among the males compared to females was similar to earlier reports among undergraduate students and the general population. ${ }^{15-17}$ The gender prevalence ratio of smoking among males and females in this study was $1.8: 1$, this is similar to narrow gender gap reported in the developed countries, but different from wider gender gap reported in another Nigeria study. ${ }^{14}$ Currently, smoking prevalence rates in women are lower than that of men, they are estimated to grow in many low- and middle-income countries. ${ }^{18}$ The projected increase in the number of smoking women was seen in this study. The rise in the number of women smoking has been attributed to more females taking up the habit in response to strong advertisement by transnational tobacco companies, whose main targets are the minors and women in educational institutions. ${ }^{14}$
Hence, the theme for the 2010 World Health Organization (WHO) 'World No Tobacco Day' was the relation between gender and tobacco, with an emphasis on marketing cigarettes to women. This theme was chosen to draw attention to the harmful effects of tobacco marketing toward women and girls. ${ }^{18}$

In this study, approximately two-third (65.4\%) commenced smoking in secondary school. This is comparable to the results obtained by Komu et $\mathrm{al}_{1}^{5}$ in their study among healthcare students reported $62.5 \%$ commencing smoking before entering the university. Oladele et $\mathrm{al}^{19}$ and Fawibe and Shittu ${ }^{14}$ in their studies reported that over $80 \%$ of students started smoking before their 18th birthday, this coincided with their secondary school age. Among those who quitted smoking, health reasons were stated as the main reason for quitting. This was in contrast to other studies which reported pressure from family or healthcare professional as the reasons for quitting. ${ }^{17,19}$ This group could be recruited as a positive model in active anti-smoking campaigns and the factors that made them quit smoking should be taken into consideration in designing anti-smoking measures.

Three hundred and five $(84.7 \%)$ of the sample agreed that smoking affected the health of the smoker, but were unaware that smoking around nonsmokers could affect their health. Among the current smokers, two-third knew the effect of smoking on health, but still smoke. The finding of this study is consistent with a previous study that reported that knowledge about health risks does not necessary act as a deterrent to smoking. ${ }^{5}$

Tobacco smoking mostly in the form of cigarettes is known as the most important environmental risk factor in periodontitis, oral cancers and precancers. ${ }^{5,10}$ It also has an adverse effect on almost all forms of periodontal therapy and increases the severity of periodontal disease. ${ }^{5}$ In the present study, majority $72.8,61.9$ and $77.2 \%$ were ignorant that smoking could affect negatively on oral health, cause oral cancers and gum disease respectively. Therefore, there is a need to educate the public on the 
harmful effect of tobacco use on oral health. In this study, the primary source of information of the effect of tobacco use among the students was media advertisement. Komu et $\mathrm{al}^{5}$ reported teaching curricula as the main source of information in his study. The study group was medical, dental and pharmacy students who at one time or the other, have been taught the health hazards associated with cigarette use. This may account for the difference.

The study was limited by the survey design, being a self-reported study, there may be under-reporting of smoking among the study population. Also, some male and female students needed some reassurance before they agreed to participate in the study.

\section{CONCLUSION}

Our study revealed that though majority $(84.7 \%)$ of the students were aware of the negative impact of smoking on general health, most of them were ignorant of the effect on oral health. Cigarette smoking is a common risk denominator for chronic noncommunicable and oral diseases; therefore a shared risk approach should be employed to educate the public on the effects of tobacco and campaign against tobacco use. Government needs to build healthy public policy that would ensure development and implementation of laws prohibiting the sale and advertisement of cigarettes, as well as banning smoking in public places.

\section{ACKNOWLEDGMENT}

We wish to thank final year students of the Faculty of Dentistry, University of Port Harcourt, who assisted in the distribution and collection of the questionnaire.

\section{REFERENCES}

1. Petersen PE. The World Oral Health Report 2003-continuous improvement of oral health in the 21st century: the approach of the WHO Global Health Program. Comm Dent Oral Epidemiol 2003;31(Suppl 1):3-24.

2. Rozi S, Butt ZA, Akhtar S. Correlates of cigarette smoking among male college students in Karachi, Pakistan. BMC Public Health 2007;7:312.

3. Jafari F, Zamani AH, Alizadeh K. Reviewing the prevalence of (cigarette) smoking and its related factors in students of Tehran University, Iran. Addict Health 2011;3-4:105-110.

4. Steptoe A, Wardle J, Cui W, Baban A, Glass K, Tsuda A, et al. An international comparison of tobacco smoking, beliefs and risk awareness in university students from 23 countries. Addiction 2002;97(12):1561-1571.
5. Komu P, Dimba EAO, Macigo FG, Ogwell AEO. Cigarette smoking and oral health among healthcare students. East Afri Med J 2009;86(4):178-182.

6. Reibel JD. Tobacco and oral diseases. Med Prin Pract 2003;1(Suppl 12):22-32.

7. Arowojolu MO, Fawole OI, Dosumu EB, Opeodu OI. A comparative study of the oral hygiene status of smokers and nonsmokers in Ibadan, Oyo state. Niger Med J 2013;54(4): 240-243.

8. Bloom B, Adams PF, Cohen RA, Simile C. Smoking and oral health in dentate adults aged 18-64. NCHS data brief, No. 85. Hyattsville, MD: National Center for Health Statistics; 2012. Available at: http://www.cdc.gov/nchs. Last accessed on May 26, 2014.

9. Nwhator SO, Ayanbadejo P, Savage KO, Jeboda SO. Oral hygiene status and periodontal treatment needs of Nigerian male smokers. TAF Prev Med Bull 2010;9(2):107-112.

10. Gautaum DK, Jindal V, Gupta SC, Tuli A, Kotwal B, Thakur R. Effect of cigarette smoking on the periodontal health status: a comparative, cross-sectional study. J Ind Soc Periodontol 2011;15(4):383-387.

11. Osungbade KO, Oshiname FO. Determinants of cigarette smoking among senior secondary school students in a rural community of Southwest Nigeria. Nig J Med 2008;17(1):40-44.

12. Salaudeen AG, Akande TM, Musa OI. Cigarette smoking prevalence and awareness of health problems of tobacco use among students of colleges of education in a North-Central State of Nigeria. Niger Med Pract 2009;55(6):17-21.

13. Salawu FK, Danburam A, Isa B, Agbo J. Cigarette smoking habits among adolescents in Northeast Nigeria. Internet J Epidemiol 2009;8(1).

14. Fawibe AE, Shittu AO. Prevalence and characteristics of cigarette smokers among undergraduates of the University of Ilorin, Nigeria. Niger J Clin Pract 2011;14(2):201-205.

15. Onadeko BO, Awotedu AA, Onadeko MO. Smoking patterns in students of higher institutions of learning in Nigeria. Afr J Med Sci 1987;16(6):9-14.

16. Awotedu AA, Jordan ER, Ndukwana OZB, Fipaza NO, Awotedu KO, Martinez J, et al. The smoking habits, attitudes towards smoking and knowledge regarding anti-smoking legislation of students in institutions of higher learning in Eastern Cape Province of South Africa. SA Fam Pract 2006;48(9):14.

17. Ayankogbe OO, Inem VA, Bamigbala OA, Roberts OA. Attitudes and determinants of cigarette smoking among rural dwellers in Southwest Nigeria. Nigerian Medical Practitioner 2003;44(4):70-74.

18. Hitchman SC, Fong GT. Gender empowerment and femaleto-male smoking prevalence ratios. Bull World Health Org 2011;89(3):195-202.

19. Oladele PO, Asaolu TO, Toriola AL, Arogbonlo S, Moselakgomo VK. Perception of Nigerian University students about the influence of cigarette advertisement on smoking habit: A questionnaire analysis. Afri J Phy Health Educ Recreation Dance 2007;13(2):505-523. 